\title{
Development of a Rural Health Framework: Implications for Program Service Planning and Delivery
}

\section{Développement d'un cadre de travail pour la santé rurale : répercussions pour la planification et la prestation de services}

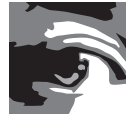 \\ DEANNA WHITE, MA \\ Epidemiologist, Haldimand-Norfolk Health Unit \\ Simcoe, ON
}

\begin{abstract}
Purpose: To describe the development and application of an evidence-based Rural Health Framework to guide rural health program, policy and service planning.

Methods: A literature review of rural health programs, focusing on health promotion, chronic disease prevention and population health, was conducted using several bibliographic databases. Findings: Thirty papers met the criteria for review, describing chronic disease interventions and public health policies in rural settings. Twenty-one papers demonstrated effective intervention programs and highlighted potential good practices for rural health programs, which were used to define key elements of a Rural Health Framework.

Conclusions: The Rural Health Framework was applied to an influenza immunization program to demonstrate its utility in assisting public health providers to increase uptake of the vaccine. This Rural Health Framework provides an opportunity for program planners to reflect on the key issues facing rural communities to ensure the development of policies and strategies that will prudently and effectively meet population health needs.
\end{abstract}




\section{Résumé}

Objet : Décrire le développement et la mise en place d'un cadre de travail fondé sur les données probantes afin d'éclairer l'établissement de programmes, lélaboration de politiques et la planification de services en santé rurale.

Méthodes: À l'aide de plusieurs bases de données bibliographiques, nous avons mené une revue de la littérature sur les programmes de santé rurale, en mettant l'accent sur la promotion de la santé, la prévention des maladies chroniques et la santé de la population.

Résultats : Trente articles - décrivant des interventions en matière de maladies chroniques et des politiques de santé publique dans les zones rurales - répondaient aux critères de la revue. Vingt-et-un articles faisaient état de programmes d'intervention efficaces et décrivaient d'éventuelles pratiques exemplaires pour les programmes de santé rurale, lesquelles ont été employées pour définir les éléments clés d'un cadre de travail pour la santé rurale.

Conclusions: Ce cadre de travail a été employé pour un programme de vaccination contre la grippe afin de démontrer son utilité pour aider les prestataires de services de santé publique à favoriser la participation au programme de vaccination. Le cadre de travail offre l'occasion aux planificateurs de programmes de penser aux enjeux clés auxquels font face les communautés rurales afin d'assurer le développement de politiques et de stratégies qui répondent judicieusement et efficacement aux besoins en matière de santé publique.

I n Canada, more than nine million people live in rural areas, representing $30.4 \%$ of the population, and rural areas constitute $95 \%$ of the land mass (PHAC 2008a; Society of Rural Physicians of Canada 2003). Rural populations are understood to have poorer levels of health status than their urban counterparts (Fertman et al. 2005; Romanow 2002). In comparison to urban areas, rural areas tend to have higher disability rates, shorter life expectancy, higher infant mortality rates and higher death rates due to injuries, circulatory and respiratory diseases, diabetes and suicide (Desmeules et al. 2006; PHAC 2008a). Challenges related to low income, poverty, lower levels of education and higher unemployment negatively affect health status of rural citizens and place them at greater risk for poorer quality of life and poorer health than those living in urban areas (Desmeules et al. 2006; Hart et al. 2005; PHAC 2008a; Romanow 2002; Smith et al. 2008).

Population health data describe the health status of the population, but do not usually explore the social determinants of health and policies underpinning variations in rural and urban health (Hart et al. 2005). Despite an abundance of health-related data at the federal, provincial and territorial levels, most do not include meaningful or purposeful rural data (Romanow 2002). The report, How Healthy Are Rural Canadians? An Assessment of Their Health Status and Health Determinants (Desmeules et al. 2006), was instrumental in addressing both the determinants of health in rural communities and the health status of those communities by using population health data. This approach required a pragmatic shift in 
Development of a Rural Health Framework: Implications for Program Service Planning and Delivery

thinking about population health. Health status is determined by a wide range of factors such as income and social status, social support networks, education and literacy, employment/ working conditions, social environments, physical environments, personal health practices and coping skills, healthy child development, biology and genetic endowment, health services and gender (PHAC 2006; Romanow 2002), all of which are influenced by whether an individual lives in a rural or an urban setting. This population-based health promotion response, which addresses comprehensive health and primary healthcare, is an effective approach to healthcare reform in rural populations (Romanow 2002). This broader way of thinking about rural health shifts from the "medical model" that encompasses evidence-based medicine to one of community capacity-building for health that also emphasizes a rural health promotion response (Kickbusch 2003; Romanow 2002).

Concerns have been raised that inadequate attention has been directed towards the determinants of health and health promotion in rural populations (Romanow 2002). A growing body of research has established that those determinants could be used to plan, sustain and improve rural health (Simon-Morton et al. 1995). The Lalonde report, A New Perspective on the Health of Canadians, was influential in Canadian health promotion history (Lalonde 1974). The report shifted attention from a disease paradigm to a new population health paradigm that emphasized a community health promotion response (Lalonde 1974). This approach enables communities to take control of and improve their overall health by leveraging a wide range of factors that determine health status (Kickbusch 1986). Of particular interest is evidence that suggests rural communities have unique characteristics with respect to health determinants, including physical environments, personal health practices and coping skills. Rural communities are often characterized by long distances, lower population density and widely dispersed population - all serving as barriers to accessing physicians, specialists, programs, services and technology (Smith et al. 2008). Also, rural communities exhibit formidable challenges in lifestyle behaviours because they have a greater incidence of unhealthy or maladaptive behaviour than their urban counterparts; for example, rural areas have reported higher smoking and obesity rates (Desmeules et al. 2006). Unhealthy behaviours in rural communities are also influenced by socio-economic factors including a higher incidence of low income and poverty, and lower levels of education, than their urban counterparts (Smith et al. 2008).

In Canada, the prevailing theoretical model that guides health policy and program planning from a chronic disease perspective is the Population Health Promotion Model (Lefebvre et al. 2006; PHAC 2002), which emphasizes the need to account for all health determinants and to view health as a multifaceted concept in which individuals' emotional, spiritual, physical and psychological needs must be met to experience optimal health. The key assumptions that underpin this model illustrate how the relationship between population health and health promotion acts on a full range of health determinants through health promotion strategies and interventions. An understanding of rural health determinants is vital if health promotion policies and strategies are to result in significant improvements in health status. Currently, 
policies and strategies for improving rural health are not typically evidence-based, focusing instead on increasing the workforce and improving access to healthcare services in remote and small rural communities rather than on government and community policies related to rural determinants of health (Romanow 2002; Smith et al. 2008). Therefore, little connection exists among rural health research, policies and health promotion programs and strategies, inevitably resulting in suboptimal programs. For example, in Ontario, local public health policies that govern chronic disease prevention programs are uniform and do not account for differences in rural and urban settings. There is a dearth of information on best practices in rural health program planning and delivery, posing a major challenge for researchers and community planners. The development of a framework that illustrates rural best practices with linkages to the social determinants of health is essential to providing high-impact programs and services. There is a growing body of evidence that these health determinants can be used to plan, sustain and improve rural health (PHAC 2002; Simon-Morton et al. 1995).

This paper describes the development and application of a Rural Health Framework, building on the Population Health Framework (PHAC 1994, 2008b) to guide evidence-based rural health program, policy and service planning. This framework is applied to an immunization program implemented by a public health unit in southwestern Ontario, Canada.

\section{Methods}

A literature review was conducted at the request of the Public Health Agency of Canada (PHAC) to identify effective rural health programs in relation to the social determinants of health, rural policy implications for public health and best practices in rural health interventions. This review was conducted using several online bibliographic databases (Academic Search Premier, Pub Med and CINAHL) and using the following keywords: intervention, prevention, systematic review, best practice, health promotion, public health, rural, remote, farming, small town, Aboriginal health, on- and off-reserve communities, chronic disease, heart health, cardiovascular disease, tobacco control, COPD, asthma, diabetes, mental health and depression, along with their risk factors, including healthy eating, active living and social determinants of health. [A more detailed outline of the search terms and parameters is available from the author.] The search parameters for this review were delineated by PHAC. Searched literature covered the period from 1998 to 2008, in order to gather most recent and up-to-date information, in English-language journals. Manual searches of the references of retrieved papers were also conducted. While initially the intent was to limit this review to papers describing programs delivered in Canada, this scope was later expanded to include literature from developing countries that might apply to the Canadian context. This search was conducted by a public health unit librarian.

Journal papers were retained for further analysis when they were (a) relevant to health promotion and chronic disease prevention, (b) relevant to population health, (c) focused on primary and secondary prevention rather than tertiary prevention and (d) the authors defined their population as rural. Defining "rural" is a challenge, as it is an elusive term whose definition shares no universal agreement among community health planners, researchers, policy makers and policy analysts (Hart 
Development of a Rural Health Framework: Implications for Program Service Planning and Delivery

et al. 2005; Smith et al. 2008). In Canada, seven main definitions of rurality exist, each emphasizing different criteria such as population size, labour market context, population density or settlement context (Statistics Canada 2001). Although from a program planning perspective these seven definitions exist, the rural small-town definition of towns or municipalities outside larger urban areas with populations of 10,000 or more has been identified as a benchmark for defining and understanding rural populations (Statistics Canada 2001). However, as there were no standardized or consistent definitions of "rural," for the purposes of this review, each study author's definitions of and criteria for rurality were accepted as meaningful in the context of the work.

For each paper included in the review, information was gathered consistent with the Population Health Promotion Model (PHAC 2002), namely the social determinants of health, the various levels within society at which health promotion activities were targeted (individual, family and community level, sector/system levels and society as a whole) and the strategies used for health promotion. In addition, information was gathered on the specific health topic, geographic location, purpose, methods, existence of evaluation data, study methods, results (effectiveness) and conclusions. These data were extracted by a research assistant and reviewed independently by a second research assistant; consensus was achieved on the data extracted.

\section{Results}

In total, 30 papers met the criteria for review (see Table 1 online at: http://www.longwoods.com/ content/23176). Papers covered a number of health issues including smoking $(n=3)$, physical activity $(n=2)$, substance use $(n=1)$ and various chronic diseases: diabetes $(n=8)$, cancer $(n=1)$, heart health $(n=5)$, policy $(n=5)$, chronic disease $(n=1)$, mental health $(n=3)$ and injury $(n=1)$. Thirteen (43\%) papers were Canadian-based, while others represented the United States ( $n=14 ; 47 \%)$ and Scandinavia $(\mathrm{n}=3 ; 10 \%)$.

Twenty-one (80.8\%) of the 26 papers that evaluated rural health interventions demonstrated effective programs and highlighted potential best practices for rural health programs (five programs were found ineffective or have yet to be proven effective; five papers describing health policy were not evaluative). Table 2 summarizes the health determinants that were studied in the reviewed papers. The majority of papers (>67\%) addressed health services and personal health practices and coping skills. Other health determinants included social environments, culture (Aboriginal communities), physical environments, social support networks and education. The number of health promotion strategies employed as outlined by the Population Health Promotion Model (PHAC 2002) ranged from one to three per intervention. Of the 21 papers that described effective health interventions, the majority involved the creation of supportive environments $(n=15 ; 71 \%)$ and personal skill development $(n=14$; $67 \%)$, two (10\%) involved the development of healthy public policy and nine (43\%) involved the re-orientation of health services. The majority of these interventions were targeted at the community ( $n=18 ; 86 \%)$ and individual $(n=12 ; 57 \%)$ levels; $10(48 \%)$ were targeted at the sector/system level and five (24\%) at the societal level. 
TABLE 2. Determinants of health studied in reviewed papers $(n=30)$

\begin{tabular}{|l|c|c|}
\hline Determinant of Health & $\mathbf{n}$ & $\%$ \\
\hline Health services & 27 & 90 \\
\hline Personal health practices and coping skills & 20 & 67 \\
\hline Social environments & 13 & 43 \\
\hline Culture (Aboriginal communities) & 5 & 17 \\
\hline Physical environments & I & 13 \\
\hline Social support networks & I & 3 \\
\hline Education & & 3 \\
\hline
\end{tabular}

A number of good practices for rural health interventions were identified in the reviewed papers; these practices are summarized in Table 3. Authors of an effective diabetes prevention program targeted to Aboriginal communities (Ho et al. 2006) suggested that multiple strategies be utilized for tailoring interventions to (a) change social norms by intervening in multiple institutions, (b) address salient concerns, (c) balance community learning preferences with proven strategies, (d) emphasize active community participation and (e) tailor programs to individual communities. Combining multiple levels of intervention (school-based, store-based and community-wide health), integrating theoretical frameworks and encouraging active involvement of community members with local cultural concepts were factors identified as important to the success of community-based programs.

In application to rural settings, a theme arising from the literature was the need for programs and models established in urban settings to be modified to suit rural populations (Greenberg et al. 2006; Potvin et al. 2003; Zavela et al. 2004) as, for example, with the implementation of programs by health professionals other than just physicians and specialists to provide clinical services ( Jin et al. 2003; Virani et al. 2006), modification of written materials to match the literacy levels of rural populations with the use of culturally appropriate examples (Mayer-Davis et al. 2004) and modified intervention activities (e.g., number and duration of physical exercise sessions), selection criteria and levels of available support to meet the unique needs of rural populations (Davis-Smith et al. 2007). As an example, an effective heart health promotion initiative offered condensed programs in order to match the seasonal rhythm of rural Saskatchewan; this six-week program was designed so that participants could complete it before the seeding of crops (Ebbesen et al. 1997).

Six papers referred to a rural research perspective on public health that has implications for policy. The common themes in the papers were community leadership and capacity, participation, community asset identification, integrated healthcare systems, rural health service delivery models, information technology, organizational networks, rural health definitions and life course research, all aimed at contributing to effective rural health planning to improve health outcomes in rural communities (Berkowitz 2004; Berkowitz et al. 2002; Hart et al. 2005; Schumaker 2002). 
TABLE 3. Good practices in minimizing rural health challenges and maximizing rural health assets for rural program planning and delivery, as identified in the literature review

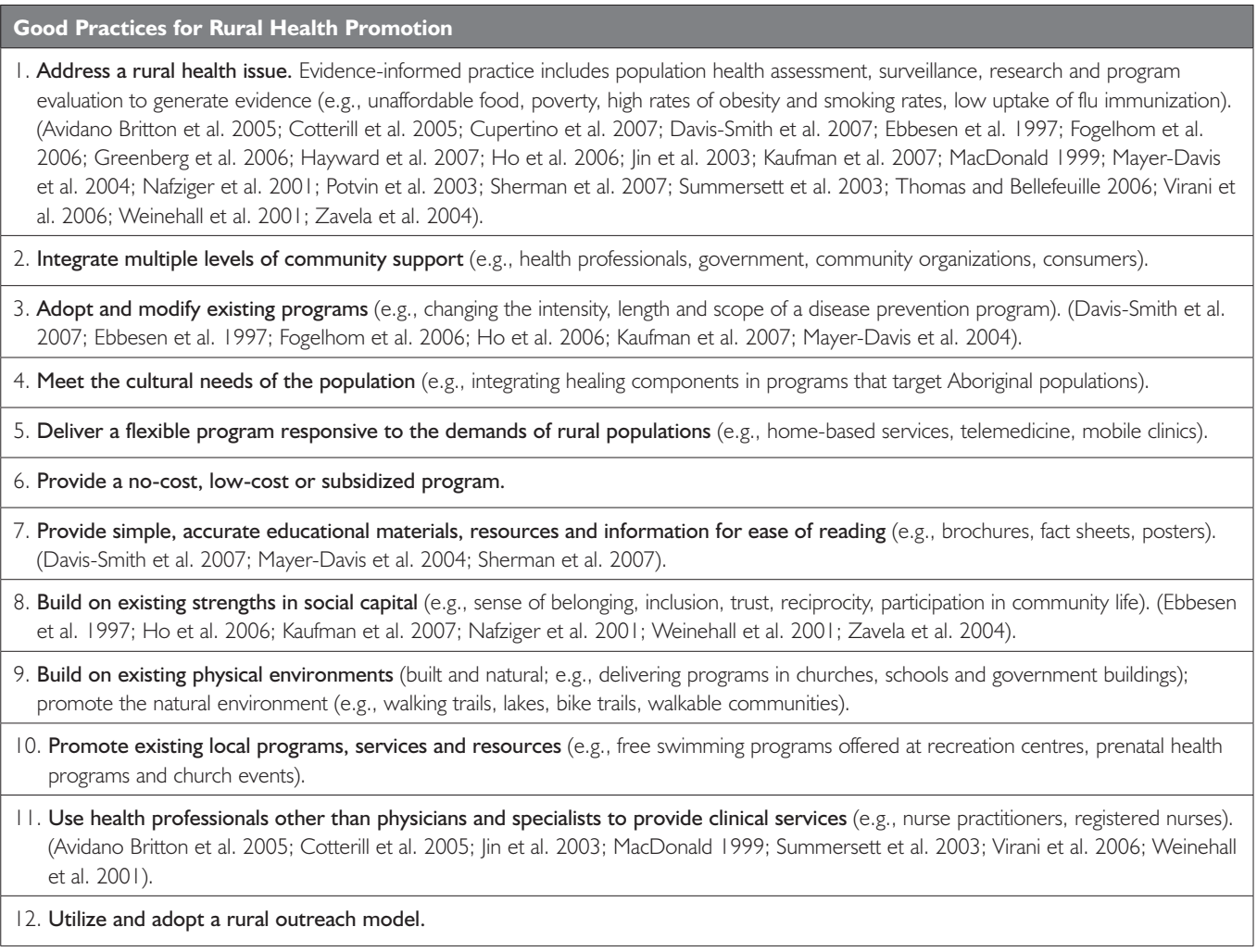

Note: Additional good practices identified in other initiatives of the Haldimand-Norfolk Health Unit include the provision of programs in several geographical areas with high population density and short distance to travel and the provision of transportation to programs (Haldimand-Norfolk Health Unit 2007).

\section{A Rural Health Framework}

From a population health approach, good practices and themes identified in the literature defined six key elements (described below) for rural health population program planning and delivery that can be used to guide the development of rural health programs and which form the foundation of the Rural Health Framework. This framework is depicted in Figure 1.

\section{Identify a rural community}

A rural population health approach identifies rural areas using a common definition. Although there is no consensus on a standardized definition, the definition selected is at the discretion of program planners. In this framework, six main approaches to defining rural areas in Canada were used, as defined by Statistics Canada (2001); each definition emphasizes different criteria such as population size, labour market context, population density or settlement context and as such, has important implications for program planning. 
FIGURE 1. A Rural Health Framework

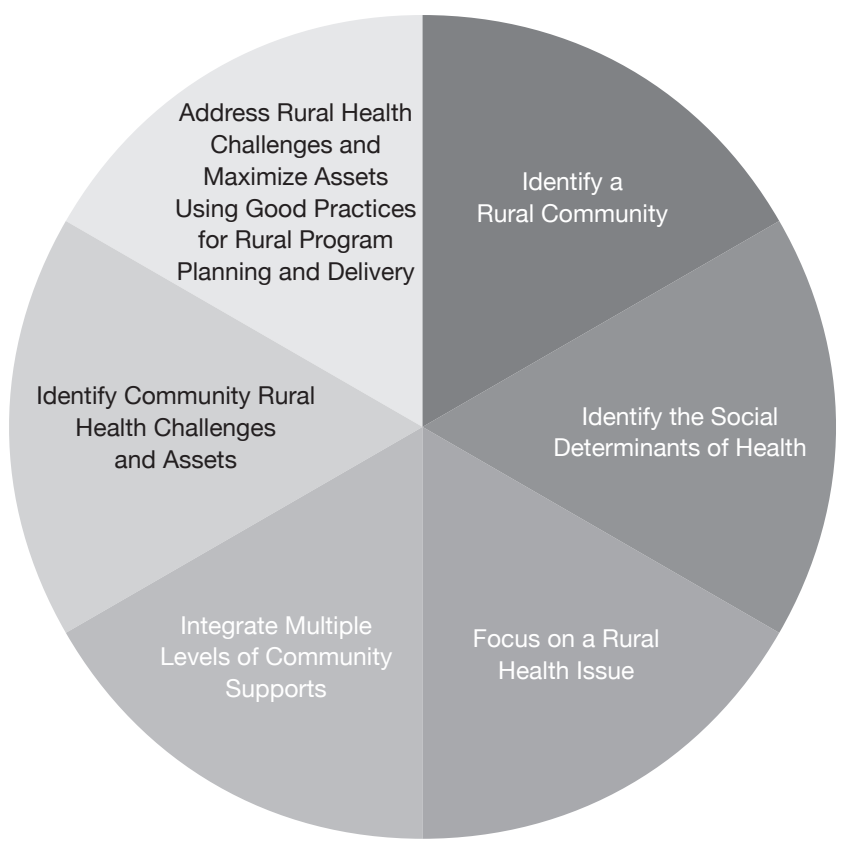

\section{Identify the social determinants of health}

A rural population health approach considers a full range of factors that influence and contribute to health (PHAC 2011b), including social environments, income and social status, education and literacy, employment/working conditions, physical environment, personal health practices and coping skills, culture, health services, healthy child development, biology and genetic endowment, social support networks and gender (PHAC 2002, 2011b).

\section{Focus on a rural health issue}

A rural population health approach uses evidence to assess the health status of the population and respond to identified needs. Evidence-informed practice uses population health assessments, surveillance, research and program evaluation to generate evidence (Ontario Ministry of Health and LongTerm Care 2008). It answers the following questions: How healthy is the rural population? How do we know? What are the community's priorities? Are there any emerging issues? What are the priority populations? How does the health of the population look over time? Is the population health status getting worse or better?

\section{Integrate multiple levels of community support}

A rural population health approach uses multiple levels of support from various sectors and levels that have a vested interest in the health of the target population in every phase of the project. Early collaboration is recommended (PHAC 2011a) and includes but is not limited to researchers, health professionals, community organizations, government and other key stakeholders. 
Development of a Rural Health Framework: Implications for Program Service Planning and Delivery

\section{Identify community rural bealth challenges and assets}

A rural population health approach calls for the identification of rural health challenges and assets using a framework based on the social determinants of health (PHAC 2011b). Challenges are informed by population health assessment, surveillance, research, program evaluation and personal experiences. Examples of challenges are access to healthcare services, geographic and social isolation, and poverty. Assets are advantages and attributes within a rural community that are vital to sustainability and growth, such as physical infrastructure (buildings), green space, social aspects of community living, agriculture and volunteerism.

\section{Address rural health challenges and maximize assets using good practices for rural program} planning and delivery

A rural population health approach involves addressing health challenges and maximizing assets using a framework based on the social determinants of health. This approach contributes in meaningful ways to the development and implementation of strategies to improve health and is based on good practices in minimizing rural health challenges and maximizing assets as identified in the literature review (see Table 3).

\section{Application of the Rural Health Framework for Program Planning and Service Delivery: Influenza Immunization Program}

To illustrate the framework's usability, program coordinators, team members and staff with the Haldimand-Norfolk Health Unit (HNHU) applied it to public health practice in several programs including its immunization program, which provides routine immunization services for infants, children, youth and adults, as well as annual flu clinics for those six months of age and older. The purpose of the immunization program is to provide resources that help minimize anxiety by emphasizing the safety and efficacy of publicly funded vaccines, and to reduce the incidence of vaccine-preventable diseases in the community. This health unit serves Haldimand and Norfolk counties, which have a combined population of 107,775 , with a population density of 37.7 people $/ \mathrm{km}^{2}$ (Statistics Canada 2009) and is considered a predominantly rural area. Multiple levels of community support can be integrated into this program: health professionals (public health nurses, nurse practitioners, physicians, pharmacists), community organizations (pharmacies, nursing agencies, community support services), government (public health, Ministry of Health and Long-Term Care, long-term care homes) and other key stakeholders (e.g., major steel and power industries). Rural health challenges and assets and generated solutions are presented in Table 4. 


\section{Deanna White}

TABLE 4. Application of the Rural Health Framework to the planning and delivery of an influenza immunization program: Identified challenges, assets and solutions for key social determinants of health

\begin{tabular}{|c|c|c|c|}
\hline $\begin{array}{l}\text { Social Determinants } \\
\text { of Health }\end{array}$ & Rural Health Challenges & $\begin{array}{l}\text { Rural Health } \\
\text { Assets }\end{array}$ & $\begin{array}{l}\text { Solutions to Health Challenges/ } \\
\text { Maximize Assets }\end{array}$ \\
\hline Social support networks & $\begin{array}{l}\text { - Geographic and social } \\
\text { isolation }\end{array}$ & $\begin{array}{l}\text { - Strong social capital (sense } \\
\text { of belonging, inclusion, } \\
\text { trust, participation in } \\
\text { community life) }\end{array}$ & $\begin{array}{l}\text { - Leverage health professionals in the } \\
\text { community to mobilize the program } \\
\text { - Foster community engagement by } \\
\text { integrating organizations and businesses } \\
\text { to implement and mobilize the program } \\
\text { (pharmacies, industry) } \\
\text { - Leverage government partnerships to } \\
\text { implement and mobilize the program. } \\
\text { - Educate nurses, health professionals and } \\
\text { the public on the vaccine's efficacy and } \\
\text { safety } \\
\text { - Encourage clients to ask questions about } \\
\text { immunization and consult with their family } \\
\text { physicians or other care providers }\end{array}$ \\
\hline Education and literacy & $\begin{array}{l}\text { - Over } 50 \% \text { of the } \\
\text { population has secondary } \\
\text { school education or less, } \\
\text { which is greater than the } \\
\text { provincial average } \\
\text { - Low literacy levels }\end{array}$ & & $\begin{array}{l}\text { - Provide simple, easy-to-read educational } \\
\text { materials on influenza and flu } \\
\text { immunization } \\
\text { - Encourage clients to ask questions about } \\
\text { immunization, their health and the health } \\
\text { of their family }\end{array}$ \\
\hline Social environments & $\begin{array}{l}\text { - Limited social support } \\
\text { services }\end{array}$ & $\begin{array}{l}\text { - Strong social and } \\
\text { community response } \\
\text { to vaccine-preventable } \\
\text { diseases }\end{array}$ & $\begin{array}{l}\text { - Provide flu clinics in various locations } \\
\text { throughout counties } \\
\text { - Leverage multiple levels of support in the } \\
\text { community to build public trust in the } \\
\text { vaccine's efficacy and safety } \\
\text { - Minimize anxiety about the vaccine's } \\
\text { safety and efficacy by educating nurses, } \\
\text { health professionals and the public on } \\
\text { the impact of influenza on absenteeism, } \\
\text { and on possible side effects and } \\
\text { contraindications } \\
\text { - Promote immunization in the community }\end{array}$ \\
\hline Physical environment & $\begin{array}{l}\text { - Limited public } \\
\text { transportation } \\
\text { - Low population density } \\
\text { - More distance to travel }\end{array}$ & $\begin{array}{l}\text { - Grand Erie District } \\
\text { School Board } \\
\text { - Catholic District } \\
\text { School Board } \\
\text { - Thriving churches }\end{array}$ & $\begin{array}{l}\text { - Utilize a rural outreach model to deliver } \\
\text { the program in several geographical areas } \\
\text { with high population density and short } \\
\text { distance to travel } \\
\text { - Provide the clinic in local schools, the } \\
\text { Norfolk Community Help Centre, the } \\
\text { Health Unit and a centrally located church } \\
\text { - Encourage community members to } \\
\text { provide transportation to residents with } \\
\text { no access to transportation }\end{array}$ \\
\hline $\begin{array}{l}\text { Personal health practices } \\
\text { and coping skills }\end{array}$ & $\begin{array}{l}\text { - Uptake of the vaccine is } \\
\text { very poor, possibly due to } \\
\text { complacency among health } \\
\text { professionals about rates } \\
\text { and existing misinformation } \\
\text { about adverse effects } \\
\text { - Over } 50 \% \text { of residents are } \\
\text { overweight or obese and } \\
\text { at high risk for influenza }\end{array}$ & & $\begin{array}{l}\text { - Promote the uptake of the influenza } \\
\text { vaccine, particularly among high-risk } \\
\text { groups } \\
\text { - Emphasize the vaccine's benefits over } \\
\text { its risks } \\
\text { - Provide resources that help minimize } \\
\text { anxiety by emphasizing the vaccine's } \\
\text { benefits, efficacy and safety. Provide } \\
\text { education on possible side effects and } \\
\text { contraindications of the vaccine as well as } \\
\text { the impact of influenza on absenteeism }\end{array}$ \\
\hline
\end{tabular}


TABLE 4. (Continued)

\begin{tabular}{|c|c|c|c|}
\hline $\begin{array}{l}\text { Social Determinants } \\
\text { of Health }\end{array}$ & Rural Health Challenges & $\begin{array}{l}\text { Rural Health } \\
\text { Assets }\end{array}$ & $\begin{array}{l}\text { Solutions to Health Challenges/ } \\
\text { Maximize Assets }\end{array}$ \\
\hline Culture & $\begin{array}{l}\text { - Anticipated increase in } \\
\text { number of citizens over } 55 \\
\text { years of age; expected to } \\
\text { increase by } 73 \% \text { between } \\
2000 \text { and } 2020 . \\
\text { - High-risk groups: nursing } \\
\text { home residents, those } \\
\text { requiring chronic care }\end{array}$ & & $\begin{array}{l}\text { - Promote the uptake of the influenza } \\
\text { vaccine, particularly among high-risk } \\
\text { groups } \\
\text { - Emphasize the vaccine's benefits over } \\
\text { the risks } \\
\text { - Provide resources/education for older } \\
\text { adults that help reduce anxiety by } \\
\text { emphasizing the efficacy and safety of } \\
\text { the vaccine, possible side effects and } \\
\text { contraindications of the vaccine as well as } \\
\text { the impact of influenza on absenteeism } \\
\text { - Offer clinics at the Community Help } \\
\text { Centre; provide translation services }\end{array}$ \\
\hline Healthy child development & $\begin{array}{l}\text { - High-risk groups: children } \\
\text { aged two to four years } \\
\text { - The percentage of } \\
\text { new mothers with low } \\
\text { education is increasing } \\
(5.2 \% \text { in } 2005 \text { to } 8.2 \% \\
\text { in 2009) }\end{array}$ & & $\begin{array}{l}\text { - Provide parents with simple, easy-to-read } \\
\text { educational materials, resources and } \\
\text { information on child immunization to help } \\
\text { promote the vaccine's efficacy and safety }\end{array}$ \\
\hline Health services & $\begin{array}{l}\text { - Low number of specialists } \\
\text { and practitioners } \\
\text { - Limited access to } \\
\text { healthcare services; many } \\
\text { travel outside counties to } \\
\text { obtain services } \\
\text { - Under-servicing of } \\
\text { children and Low German } \\
\text { Mennonites } \\
\text { - Few walk-in clinics } \\
\text { - Difficult to recruit and } \\
\text { retain specialists and } \\
\text { practitioners }\end{array}$ & $\begin{array}{l}\text { - Three general hospitals in } \\
\text { the area }\end{array}$ & $\begin{array}{l}\text { - Provide free and accessible flu clinics } \\
\text { within the community }\end{array}$ \\
\hline
\end{tabular}

The application of the Rural Health Framework has assisted public health providers in providing more appropriate and adequate resources to help minimize anxiety by emphasizing the vaccine's benefits, efficacy and safety, and to increase uptake of the vaccine. The framework was valuable in raising awareness about the specific challenges to immunization that are unique to rural communities so that effective strategies could be developed to overcome these. Although the initial focus was to apply the framework only to chronic disease programs, it was clearly adaptable to any rural health program. This adaptability illustrated the framework's broad utility and demonstrated that rural health programs and approaches can be more effective when related to health determinants. The framework has also been used in information program evaluation aimed at delineating impacts through a program review process that is currently underway.

\section{Discussion}

Unlike other health promotion frameworks, in the Rural Health Framework, health promotion approaches and programs are linked to understand the rural community, emphasize rural health assetmapping and identify challenges. The framework approaches the planning and delivery process by 
breaking it into smaller, more manageable pieces. The elements also demonstrate linkages in a continuous cycle. One of the framework's contributions is that it encourages more comprehensive planning of health promotion programs from a rural perspective. Frameworks of this type can assist program planners in improving the health status of a rural community. The lack of information on best practices for health planning in rural areas challenges program planners to develop relevant and effective health promotion programs for rural communities. The Rural Health Framework described here provides an opportunity for policy makers and program planners to reflect on the key issues facing rural communities to ensure the development of strategies that will prudently and effectively meet population health needs. Based on a rural perspective, frameworks of this type have the potential to assist program planners in improving the health status of a rural community.

Applying the framework to existing programs within the health unit made evident the fact that these programs, without formal documentation, already incorporated aspects of the Rural Health Framework and employed key elements of rural program planning and delivery. This finding afforded staff the opportunity to showcase their programs and secure their position as "leaders in rural health." The framework also provided an opportunity to identify gaps in service with the development of action strategies to overcome these gaps.

The ultimate aim of the Rural Health Framework is to assist program planners in improving the health status of rural populations. Limitations of the framework that require further exploration include the lack of an evaluation component as well as a promotion and communication strategy. Further research is needed to demonstrate significant changes in specific health indicators (e.g., incidence of influenza A, incidence of diabetes, smoking rates, obesity rates, mortality due to cardiovascular disease) and health behaviours (e.g., number of influenza vaccines administered, enrolment in local exercise programs, attendance at wellbaby and breastfeeding drop-in clinics). Further research, using qualitative approaches, is also needed on the perspectives of program planners using this framework in terms of ease of use, challenges, gaps and opportunities for improvements. More research is needed on the framework's efficacy when applied early in the planning process and development phases of new health programs. Further validation may be provided by more comprehensive searches of the literature, including programs completed in international settings and described in the grey literature, the lack of which in this current review is a limitation.

\section{ACKNOWLEDGEMENTS}

The author wishes to acknowledge the following individuals for their feedback and contributions on earlier reports of this project: Dr. Malcolm Lock, Jill Steen, Pattie Moore, Jackie Esbaugh, Michelle Crowley, Michele Pasichnyk, Kristal Pitter, Melanie Laundry, Mona Aaltonen, Angie (Redecop) Alward, Angela Campbell, Maria Mendes Wood, Rose Huyge, RoseAnne Maracle and Sabine Murphy.

Correspondence may be directed to: Deanna White, MA, Epidemiologist, Haldimand-Norfolk Health Unit; tel.: 519-426-6170 ext. 3215; fax 519-426-9974; e-mail: deanna.white@hnhu.org. 


\section{REFERENCES}

Avidano Britton, G.R., J. Brinthaupt, J. Stehle and G. James. 2005. “The Effectiveness of a Nurse-Managed Perinatal Smoking Cessation Program Implemented in a Rural County." Nicotine and Tobacco Research 8: 13-28.

Balamurugan, A., M. Rivera, K Sutphin and D. Campbell. 2007."Health Communication in Rural America: Lessons Learned from an Arthritis Campaign in Rural Arkansas." Journal of Rural Health 23(3): 270-275.

Berkowitz, B. 2004. "Rural Public Health Service Delivery: Promising New Directions." Journal of Public Health 94: 1678-81.

Berkowitz, B., J. Ivory and T. Morris. 2002. "Rural Public Health: Policy and Research Opportunities." Journal of Rural Health 18: 186-96.

Cotterill, M., R. Gasparelli and E. Kirby. 2005. "Colorectal Cancer Detection in a Rural Community." Canadian Family Pbysician 51: 1224-28.

Cupertino, P., J.D. Mahnken, K. Richter, L.S. Cox, G. Casey, K. Resnicow et al. 2007. "Long-Term Engagement in Smoking Cessation Counselling among Rural Smokers." Journal of Health Care for the Poor and Underserved 181: 39-51.

Daniel, M., L.W. Green, S.A. Marion, D. Gamble, C.P. Herbert, C. Hertzman et al. 1999. “Effectiveness Of Community-Directed Diabetes Prevention and Control in a Rural Aboriginal Population in British Columbia, Canada." Social Science and Medicine 48(6): 815-832.

Davis-Smith, Y.M., J.M. Boltri, J.P. Seale, S. Shellenberger, T. Blalock and B. Tobin. 2007. “Implementing a Diabetes Prevention Program in a Rural African-American Church." Journal of the National Medical Association 99: 441-46.

Desmeules, M., R. Pong, C. Legacé, D. Heng, D. Manuel, R. Pitblado et al. 2006. How Healthy Are Rural Canadians? An Assessment of Their Health Status and Health Determinants. Ottawa: Canadian Institute for Health Information.

Ebbesen, L., V. Ramsden, B. Reeder and T. Hamilton. 1997. "Heart Health in Rural Saskatchewan." Canadian Nurse 93: 27-30.

Estey, E., A. Kmetic and J. Reading. 2007."Innovation Approaches in Public Health Research." Canadian Journal of Public Health 98(6):444-446.

Fertman, C., S. Dotson, G. Mazzocco and S. Reitz. 2005. "Challenges of Preparing Allied Health Professional for Interdisciplinary Practice in Rural Areas." Journal of Allied Health 34: 163-68.

Fogelhom, M., R. Valve, P. Absetz, H. Heinonen, A. Uutela, K. Patja et al. 2006."Rural-Urban Differences in Hand Health Behaviour: A Baseline Description of a Community Health Promotion Programme for the Elderly." Scandinavian Journal of Public Health 34: 632-40.

Greenberg, N., K. Boydell and T. Volpe. 2006. "Paediatric Telepsychiatry in Ontario: Caregiver and Service Provider Perspectives." Journal of Behavioral Health Services and Research 33: 105-11.

Haldimand-Norfolk Health Unit. 2007. Rural Health: A Qualitative Research Approach to Understanding Best Practices for Rural Health Service Delivery in a Public Health Setting. Simcoe, ON: Author.

Hart, G., E. Larson and D. Lishner. 2005. "Rural Definitions for Health Policy and Research.” American Journal of Public Health 95: 1149-55.

Hayward, L.M., H.S. Campbell and C. Sutherland-Brown. 2007. "Aboriginal Users of Canadian Quitline: An Exploratory Analysis." Tobacco Control 16: i60-i64.

Ho, L.S., J. Gittelsohn, S.B. Harris and E. Ford. 2006. “Development of an Integrated Diabetes Prevention Program with First Nations in Canada." Health Promotion International 21: 88-97.

Huot, I., G. Paradis, and M. Ledoux. 2004. "Effects of the Quebec Heart Health Demonstration Project on Adult Dietary Behaviours." Preventive Medicine 38: 137-148.

Jin, A.J., D. Martin, D. Maberley, K.G. Dawson, D.W. Seccomber and J. Beattie. 2003. “Evaluation of a Mobile Diabetes Telemedicine Clinic Serving Aboriginal Communities in Northern British Columbia, Canada." Circumpolar Health 63: 124-28.

Kaufman, A.V., F.R. Scogin, L.D. Burgio, M.P. Morthland and B.K. Ford. 2007. "Providing Mental Health Services to Older People Living in Rural Communities." Journal of Gerontological Social Work 48: 349-65.

Kickbusch, I. 1986. "Health Promotion: A Global Perspective." Canadian Journal of Public Health 77: 321-26. 


\section{Deanna White}

Kickbusch, I. 2003."The Contribution of the World Health Organization to a New Public Health and Health Promotion." American Journal of Public Health 93: 383-88.

Lalonde, M. 1974. A New Perspective on the Health of Canadians. Ottawa: Health and Welfare Canada.

Lee, B.C., J. Westaby and R.L. Berg. 2004. “Impact of a National Rural Youth Health and Safety Initiative: Results from a Randomized Controlled Trial." American Journal of Public Health 94(10): 1743-1749.

Lefebvre, S., C. Warren, S. Laclé and P. Sutcliffe. 2006. “A Framework to Integrate Social and Economic Determinants of Health into the Ontario Public Health Mandate." Sudbury, ON: Sudbury \& District Health Unit.

MacDonald, S. 1999."The Cardiovascular Health Education Program. Assessing the Impact on Rural and Urban Adolescents' Health Knowledge." Applied Health Research 12: 86-90.

Mayer-Davis, E.J., A. D’Antonio, S. Smith, G. Kikner, S. Martin, D. Parra-Medina et al. 2004.“Pounds Off with Empowerment (POWER): A Clinical Trial of Weight Management Strategies for Black and White Adults with Diabetes Who Live in Medically Underserved Rural Communities." American Journal of Public Health 94: 1736-42.

Nafziger, A.N., L. Weinehall, C. Lewis, P.L. Jenkins, T.A. Erb, T.A. Pearson et al. 2001.“Design Issues in the Combination of International Data from Two Rural Community Cardiovascular Intervention Programs." Scandinavian Journal of Public Health 29: 33-39.

Ontario Ministry of Health and Long-Term Care. 2008. The Ontario Public Health Standards. Toronto: Queen's Printer for Ontario.

Potvin, L., M. Cargo, A.M. McComber, T. Delormier and A.C. Macaulay. 2003.“Implementing Participatory Intervention and Research in Communities: Lessons from Kahnawake Schools Diabetes Prevention Project in Canada." Social Science and Medicine 56: 1295-305.

Public Health Agency of Canada (PHAC). 1994. "Strategies for Population Health: Investing in the Health of Canadians" (figure, p. 30). Retrieved December 6, 2012. <http://www.phac-aspc.gc.ca/ph-sp/pdf/strateg-eng.pdf >. Public Health Agency of Canada (PHAC). 2002. Population Health: An Integrated Model of Population Health and Health Promotion. Ottawa: Author.

Public Health Agency of Canada (PHAC). 2006. "Information: Determinants of Health." Retrieved October 15, 2012. <http://www.phac-aspc.gc.ca/ph-sp/phdd/determinants/determinants.html\#income>.

Public Health Agency of Canada (PHAC). 2008a."Health Topics: Rural Health." Retrieved August 5, 2008. $<$ http://www.phac-aspc.gc.ca/ccdpc-cpcmc/topics/rural_e.html>.

Public Health Agency of Canada (PHAC). 2008b. "Towards a Common Understanding: Clarifying the Core Concepts of Population Health." Retrieved December 6, 2012. <http://www.phac-aspc.gc.ca/ph-sp/docs/common-commune/appendix_b-eng.php>.

Public Health Agency of Canada (PHAC). 2011a."Population Health Approach: The Organizing Framework." Canadian Best Practices Portal. Retrieved December 6, 2012. <http://66.240.150.14/population_health/indexeng.html>.

Public Health Agency of Canada (PHAC). 2011b. “What Determines Health?” Retrieved December 6, 2012. $<$ http://www.phac-aspc.gc.ca/ph-sp/determinants/index-eng.php>.

Romanow, R. 2002. Building on Values: The Future of Health Care in Canada. Saskatoon: Commission on the Future of Health Care in Canada.

Schumaker, A.M. 2002. "Interorganizational Networks: Using a Theoretical Model to Predict Effectiveness of Rural Health-Care Delivery Networks." Journal of Health Human Services Administration 25: 371-406.

Sherman, B.J., G. Gilliland, J.L. Speckman and K.M. Freund. 2007."Effect of a Primary Care Exercise Intervention for Rural Women." Preventive Medicine 44: 198-201.

Simon-Morton, B.G., W.H. Greene and N.H. Gottlieb. 1995. Introduction to Health Education and Health Promotion. Prospective Heights, IL: Waveland Press.

Smith, K.B., J.S. Humphreys and M.G. Wilson. 2008. "Addressing the Health Advantages of Rural Populations: How Does Epidemiological Evidence Inform Rural Health Policies and Research?" Australian Journal of Rural Health 16: 56-66.

Society of Rural Physicians of Canada. 2003. Primary Care Renewal Policy: Recommended Rural Strategies. Shawville, QC: Author. 
Statistics Canada. 2001. Rural and Small Town Canada: Analysis Bulletin. Definitions of Rural. Retrieved December 6, 2012. <http://www.statcan.gc.ca/pub/21-006-x/21-006-x2001003-eng.pdf.>.

Statistics Canada. 2009. Haldimand and Norfolk Health Unit Community Profiles. Ottawa: Author.

Summersett, G.M., G.E. Richards, S.M. Melzer, J.R. Sugarman and G.M. Kletter. 2003. "Effectiveness of a Rural Paediatric Diabetes Management Program." Paediatric Diabetes 4: 137-42.

Thomas, W. and G. Bellefeuille. 2006. "An Evidence-Based Formative Evaluation of a Cross-Cultural Aboriginal Mental Health Program in Canada." Advances in Mental Health 5: 202-15.

Virani, S., D. Strong, M. Tennant, M. Greve, H. Young, S. Shade et al. 2006. "Rationale and Implementation of the SLICK Project: Screening for Limb, I-eye, Cardiovascular and Kidney (SLICK) Complications in Individuals with Type 2 Diabetes." Canadian Journal of Public Health 97: 241-47.

Weinehall, L., G. Hellsten, K. Boman, G. Hallmans, K. Aspund and S. Wall. 2001. “Can a Sustainable Community Intervention Reduce the Health Gap? A 10-Year Evaluation of a Swedish Community Intervention Program for the Prevention of Cardiovascular Disease." Scandinavian Journal of Public Health 29: 59-68.

Zavela, K., V. Battistich, C.A. Gosselink and B. Dean. 2004. "Say Yes First: Follow-up of a Five-Year Rural Drug Prevention Program." Journal of Drug Education 34: 73-88. 